\title{
6G and the UN SDGs: Where is the Connection?
}

\author{
Marja Matinmikko-Blue ${ }^{1}$ (D) Seppo Yrjölä ${ }^{1,2} \cdot$ Petri Ahokangas $^{3}$ (D) $\cdot$ Kirsi Ojutkangas $^{4}$. \\ Elina Rossi ${ }^{5}$
}

Accepted: 16 August 2021 / Published online: 31 August 2021

(c) The Author(s) 2021, corrected publication 2021

\begin{abstract}
Sustainability has entered all aspects of life, calling for an active approach from the wireless and mobile communications community to help in solving fundamental challenges facing societies. Societal, economic, and environmental aspects of sustainability have become increasingly important design criteria in developing future technologies, along with the United Nations Sustainable Development Goals (UN SDGs) framework that sets specific goals and targets to be achieved by 2030 . The role of mobile communications is important in supporting nations and organizations in meeting the UN SDGs in a timely manner, but the whole ICT sector itself, with its critical role as the backbone of society, can create a significant sustainability burden. Research on the next-generation mobile communication networks (6G) has started, aiming at first deployments in 2030, in a new era where sustainability defines its development. Therefore, sustainability, especially through the UN SDGs, and the future $6 \mathrm{G}$ wireless networks, cannot be treated in isolation, but a clear connection between them is urgently needed. This paper extends from traditional green communications and energy efficiency considerations in wireless communications to establishing a close connection between $6 \mathrm{G}$ and the triple bottom line of economic sustainability, societal sustainability, and environmental sustainability. The paper outlines open research challenges for sustainable $6 \mathrm{G}$ development and provides a set of research questions encouraging especially the researchers and engineers in the wireless and mobile communications community to address to realize a sustainable future.
\end{abstract}

Keywords $5 \mathrm{G} \cdot 6 \mathrm{G} \cdot \mathrm{ICT} \cdot \mathrm{SDG} \cdot$ Sustainability $\cdot$ Sustainable development

Marja Matinmikko-Blue

marja.matinmikko@oulu.fi

Seppo Yrjölä

seppo.yrjola@nokia.com

Petri Ahokangas

petri.ahokangas@oulu.fi

1 Centre for Wireless Communications (CWC), University of Oulu, Oulu, Finland

2 Nokia, Oulu, Finland

3 Martti Ahtisaari Institute, Oulu Business School, University of Oulu, Oulu, Finland

$4 \quad$ Research and Project Services, University of Oulu, Oulu, Finland

5 Faculty of Information Technology and Electrical Engineering, University of Oulu, Oulu, Finland 


\section{Introduction}

Sustainability has become a key influential factor in virtually all aspects of society. The development of any new technology can no longer occur in isolation from sustainability considerations. Yet, the definitions and approaches for sustainability and sustainable development are highly context-specific, creating a complicated environment to operate in. The 2030 Agenda for Sustainable Development by the United Nations defines a framework for sustainable development including 17 Sustainable Development Goals (SDGs) with detailed targets measured through a set of indicators that countries are committed to achieving by 2030 [1]. This UN SDG framework is the major global sustainability driver, and its principles are increasingly finding their way to regional and national level strategies, see e.g. European Green Deal [2]. Also, the wireless and mobile communications research needs to address the UN SDG framework in a comprehensive and timely manner [3].

Sustainability and sustainable development can generally be considered from three interdependent perspectives, often referred to as the triple bottom line of economic sustainability, societal sustainability, and environmental sustainability [4]. For managing their interdependence, the demands stemming from these perspectives should be balanced, not compromised [5]. If economic sustainability aims to secure profitability and liquidity, societal sustainability aims to contribute to human and societal capital, and environmental sustainability refers to the consumption of reproducible resources [6]. In addition, the requirements for circularity should be considered in sustainable development by moving from the linear model of "take, make, use, and dispose" to the circular model "reduce, reuse, recycle, recover, remanufacture, and redesign" at product, process and system-level of analysis [7].

Information and communication technologies (ICT) are important enablers in the path towards a sustainable future. ICT present a diverse set of technological tools and resources used to transmit, store, create, share or exchange information, such as computers, the Internet, fixed or mobile networks etc. [8]. ICT and, more specifically, mobile communication networks and devices play a critical role in today's society as the backbone for virtually all sectors of society, and this role is further expected to increase in the future. The wireless and mobile communication sector has the potential to transform the operations of several other sectors towards sustainability $[9,10]$. At the same time, the impact of the whole ICT sector itself on sustainability, including its climate and environmental impact, is significant and needs to be thoroughly addressed, see $[11,12]$.

The ICT sector in general and the mobile communications sector specifically have a close connection with the UN SDG framework [1, 13] as outlined in [9, 10, 14-20]. Mobile communication solutions can contribute to, for example, alleviating hunger through enhancing food production, making quality education available in remote locations, accessing health services remotely, or promoting gender equality by providing access to information. Yet, also their development needs to be ecological and societally just. Future 6G systems are expected to emerge in 2030, after an intensive research and development phase that usually takes a decade for each new generation of mobile communication technologies. The development of this new technology does not appear in a vacuum but is increasingly targeted at solving underlying societal challenges. In fact, in the world's first white paper on 6G, the UN SDGs are identified as a key driver for 6G [21].

What is meant with sustainability is often context-specific, leading to diverging approaches for introducing sustainability into the development of the new technology. This 
paper aims at clarifying sustainable development in the context of research and development of future 6th generation mobile communication networks $(6 \mathrm{G})$. The paper introduces different sustainable development perspectives focusing on the internationally agreed UN SDG framework [1]. Building on the initial work in [3], the paper further outlines a connection between $6 \mathrm{G}$ and the UN SDGs to guide the development of this new technology. Finally, the paper proposes fundamental research topics for the mobile communication community to address for realizing a sustainable future through $6 \mathrm{G}$.

The rest of this paper is organized as follows. Section 2 presents the background on sustainable development in the context of mobile communications, focusing on the UN SDG framework. Section 3 presents visions for $6 \mathrm{G}$, as outlined in the community. Section 4 outlines a connection between $6 \mathrm{G}$ and the UN SDGs. Section 5 presents topics for further research on sustainable $6 \mathrm{G}$, followed by conclusions in Sect. 6 .

\section{Understanding the Connection Between Mobile Communications and Sustainability}

Sustainability has entered all aspects of society. There are many understandings of sustainability, most notably including the 2030 Agenda for Sustainable Development by the United Nations $[1,13]$. This chapter presents an overview of the state of the art of the connection between sustainable development and mobile communications, considered from different perspectives, including environmental, societal, and economic sustainability [4], and specifically focusing on using the UN SDG framework.

\subsection{Sustainable Development and Mobile Communications}

New technologies such as $6 \mathrm{G}$ promise significant opportunities for new value creation and profiting from innovation [22]. However, from the perspective of sustainable development, the emerging, enabling, and embedding nature of technology is important to address [23]. First, as there are often several initial variations of a technology, the lifecycle of that technology should be considered from the beginning. Second, as technologies are commercialized in multiple application domains, they might lead to significant societal outcomes and requirements for complementarity and extendibility. Third, in developing a technology, the business models and ecosystems where the technology is commercialized need to be carefully considered. Each emerging, enabling, and embedding technology element could represent a different source of value co-creation and co-capture for a developed technological solution.

The different perspectives of sustainability need to be considered in parallel and as balanced and uncompromised: environmental sustainability should be sought without sacrificing economic and societal progress; societal values should be sought without compromising economic and environmental sustainability; and finally, economic sustainability should be sought without causing negative societal or environmental consequences (c.f. [5]). Figure 1 summarizes the different sustainability viewpoints for sustainable development. For achieving integrated sustainability [24], attention in the wider context of digitalization and digital technologies needs to be paid to achieving agility and proactiveness toward emerging opportunities and resilience in terms of continuity and value conservation [5]. In addition, integrated sustainability means moving from mere efficiency-orientation 


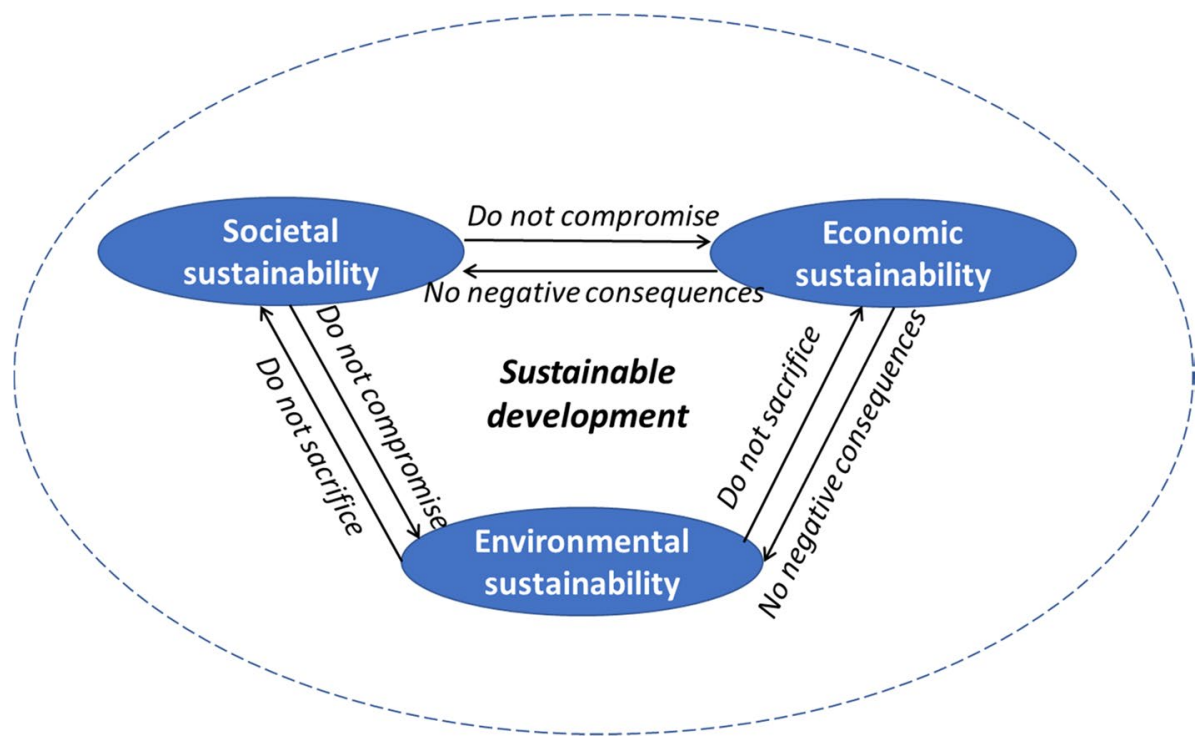

Fig. 1 Interrelations of societal, economic, and environmental sustainability in sustainable development

to considering effectiveness in the triple bottom line of economic sustainability, societal sustainability, and environmental sustainability [4].

Regarding environmental sustainability, an approach of 6Rs-reduce, reuse, recycle, recover, remanufacture, and redesign_-presented in [25, 26] and originally developed for assessing the sustainability of manufactured goods, can be used. The 6R approach extends with slight modifications to develop new technologies. 'Reduce' provides guidelines for reducing resource usage, energy consumption, waste, and health hazard, while 'reuse' points to the use of reusable materials in general at product (including its components and complements and extensions), process, and (eco)systems levels over the whole lifecycle of technology and minimize the use of new material. 'Recycle', in turn, refers to the conversion of waste into something usable after the post-use cycle. 'Recover' denotes collecting end-of-life products and recovering what is reusable for (other) post-use. 'Redesigning' offers flexibility for remanufacturing process but especially allows for complementarity and extendibility of a technology and its function. Finally, 'remanufacture' refers to the re-processing of used products, processes, and systems or restoring the original state or possible new form.

Regarding sustainable development in the ICT domain, authors in [27] have introduced a framework for constructive sustainability assessment for emerging technologies as part of a broader approach. They distinguish two levels of environmental impacts from ICT, on the one hand, related to the life cycle of hardware and the other related to how the applications are being used. This is aligned with the view from [18] and [19] that while ICT in general and mobile communications are explicitly often seen as a means to reduce $\mathrm{CO} 2$ emissions on a global scale by developing smarter cities, transportation, or electrical grids to save energy, they are a significant source contributing to the increasing levels of $\mathrm{CO} 2$ emissions through the production of devices and as a source of electronic waste.

In the wireless and mobile communications networks domain, much attention has been paid to environmental sustainability, typically understood through energy and other 
resource efficiencies [28, 29], especially in the form of "green communications" [29, 30]. The authors in [31] review 20 years of research on "green radios." This research considers spectrum efficiency and energy efficiency in wireless networks and end-user devices as essential for sustainability, highlighting the ever-increasing role of green radios in future networks. Fundamental green tradeoffs for 5G networks are presented in [29] focusing on the theoretical relations between the pairs of spectrum efficiency, energy efficiency, deployment efficiency, delay, power, and bandwidth.

Authors in [32] create a systems engineering approach for 5G in creating a sustainable society, highlighting three key domains: the policymaker, the industry, and the market in the sustainability development. A mobile network operator (MNO) perspective on 5G from a sustainability viewpoint is given in [33] where the energy consumption of the radio access network is assessed with different load conditions. The MNO view is further studied in [34] from the point of the environmental and financial feasibility of MNOs becoming carbon neutral. Energy efficiency for 5G networks is studied in more detail in [35] where methods for evaluating and reducing the network's energy consumption are presented. A survey of metrics and measurement tools for sustainable cloud networks in [36] divides the sustainability treatment into corporate-level, facility-level, network-level, equipmentlevel, and component-level approaches, focusing on energy consumption and greenhouse gas emissions.

Sustainability for very high capacity mobile and fixed networks is studied in [37]. The focus on sustainability is reducing bit rate through video compression, reducing packet loss rates through intelligent algorithms, and reducing round-trip time with edge computing. Energy-efficient backhauling for ultra-dense 5G small cell networks is studied in [38] by optimizing the use of both passive optical networks and wireless millimeter-wave backhauling solutions for energy savings.

The network functions virtualization (NFV) paradigm that is rapidly entering the mobile communication networks in 5G is considered in [39], where a carbon footprint estimation model is proposed to assess the environmental sustainability of NFV through energy consumption. The authors conclude that despite the promise of NFV to optimize resource use through the use of virtual resources, the sustainability impact of NFV in its current implementation is higher, indicating that the energy consumption aspect of NFV must be seriously addressed in its current implementation the design of NFV architectural paradigms.

\subsection{UN SDG Framework and Mobile Communications}

Agenda 2030 for sustainable development by the United Nations [1] consists of 17 goals that cover major global challenges to be achieved by 2030. The goals are further detailed into 169 targets, which are measured with 231 unique indicators. The UN SDG framework presents a comprehensive action plan whose achievement can be significantly contributed to with the use of wireless and mobile communications solutions in various sectors of society. However, out of the 231 indicators, only seven indicators are identified as ICT-related and they address only four SDGs (SDG \#4: Quality education; \#5: Gender equality; \#9: Industry, innovation \& infrastructure; and \#17: Partnerships). These ICT related indicators include the proportion of schools with access to the Internet for pedagogical purposes; the proportion of schools with access to computers for pedagogical purposes and proportion of youth/adults with ICT skills, by type of skills; the proportion of individuals who own a mobile telephone; percentage of the population covered by a mobile network, broken down 
by technology; and fixed Internet broadband subscriptions, broken down by speed and proportion of individuals using the Internet.

In reality, there is a close linkage between ICT/mobile communications and each of the 17 UN SDGs, as illustrated in Table 1. In general, the role of mobile communications in contributing to the UN SDGs follows a three-layer approach: deployment of infrastructure and networks that form the foundation for the digital economy; providing access and connectivity allowing people to use mobile services; and enabling services and relevant content for people [9, 10, 40-42].

Prior work on the connection between mobile communication networks and the UN SDGs has used the classification of economic, social and environmental SDGs [17]. However, instead of looking at all UN SDGs through these three different perspectives, the work in [17] divided the SDGs into three and concluded that UN SDGs \#1, \#2, \#3, \#8 and \#9 are economic SDGs, UN SDGs \#4, \#5, \#10, \#11, \#16, and \#17 are social SDGs, and UN SDGs \#6, \#7, \#12, \#13, \#14, \#15 are environmental SDGs. However, treating the UN SDGs separately and categorizing them into the economic, social, and environmental sustainability approaches (see Chapter 2.1) has limitations since they are cross-cutting across the UN SDGs. While the UN SDGs present a helpful approach by setting concrete goals and targets to achieve sustainability measured with indicators [1], it does pose challenges. Authors in [45] point out, e.g., that the UN SDGs are largely detached from the international legal system and are not legally binding. Eisenmenger et al. [46] criticize the goals for prioritizing economic growth over sustainable resource use and Wiedmann et al. [47] for them to be coupled with GDP growth (SDG \#8), which in fact, contradicts some of the SDGs (e.g., \#12 and \#13).

The corporate-level sustainability of the ICT sector from the UN SDG perspective is studied in [48] where an evaluation framework is proposed, based on the UN SDGs, to analyze at the firm level, including themes such as energy efficiency, materials/resources recycling/efficiency, supply chain management, air pollutants, waste, and water. Authors in [49] have noted that the progress in meeting the UN SDGs has been hampered by the lack of data available to measure the indicators in the UN SDG framework and propose an interdisciplinary program of research about artificial intelligence (AI) techniques.

Furthermore, mapping each of the 17 UN SDGs with corresponding mobile communication topics is a valuable starting point for understanding the complex connection between the two themes. However, the achievement of one SDG can negatively impact the achievement of another SDG due to their interrelations. Therefore, the topic of cross-cutting themes (entry points) has been introduced to consider the whole [50]:

- Obstacles to human well-being and capabilities,

- Sustainable and just economies,

- Food systems and nutrition patterns,

- Energy decarbonization with universal access,

- Urban and peri-urban development, and

- Global environmental commons.

These themes contribute to several individual UN SDGs and offer the most promise for achieving the desired transformations. Sustainability should not be approached by targeting a single goal but rather by looking at the big picture. Negative tradeoffs should be negotiated in order to approach sustainability in a balanced manner. The entry points enable access to the underlying systems. By prioritizing individual goals alone, there is a risk of unbalanced attention given to the UN SDGs [50] entry points. 
Table 1 The connection between mobile communications and the UN SDGs

\section{UN SDG Connection to mobile communications}

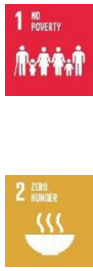

ICT technologies connect the unconnected, bringing access to information, education, healthcare and more significant economic opportunity [14]. Mobile communications can provide communication infrastructure to stimulate local economy growth in poor communities; lower barriers to access economic resources by providing access to mobile money and micro-financing; and generate employment opportunities for people living in extreme poverty [42]

Connectivity, IoT applications and sensors, AI, Machine Learning bring faster access to information and greater efficiency across industry and agriculture. ICT helps farmers improve crop yields and business productivity through better access to market information, weather forecasts, training programs, and other tailored online content [10]. Precise location and time data will enable autonomous farm robots that can perform continuous weed control with pinpoint accuracy. Therefore, farmers could significantly reduce their use of herbicides, minimizing the impact on soil/water quality and protecting biodiversity [14]

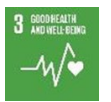

Mobile communications enable communication with medical practitioners, monitor well-being through mobile, provide access to health programs, provide digital identity service to access healthcare, improve water quality through IoT, and provides big data for epidemics [42]. As the digitalization and connectivity of healthcare grows, the complexity of robots, telemetry, remote surgery solution requires trustworthy networks. Access to data and data ownership are vecinubg more important factors in value creation. However, limiting access is one of the means to control and restricti empowerment [3]

ICT powers a revolution in digital learning; mobile devices allow students to access learning assets anytime, anywhere; teachers use mobile devices for everything from literacy and numerical training to interactive tutoring; mobile learning can help break down economic barriers, divides between rural and urban, as well as the gender divide [10]. Education powered by the Internet of Skills and the Internet of Senses will enable specialization from the school system's early grades. Learning will be tightly connected to personal data to react to any disturbance and ensure a successful study track based on individual interests. Students will be able to choose virtual courses and degrees from any university globally and visit digital twin campuses for interaction. Global networking during studies will support international career planning, which is done partly remotely [43]

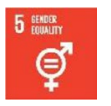

Mobile phones can help women in low- and middle-income countries feel safer and more connected. They also provide access to information, services and life-enhancing opportunities. Mobile can connect women to sharing economy and allow access to female-specific (e-health) services [9]

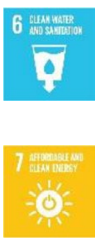

ICT enables intelligent water management, facilitating the measurement and monitoring of water supplies as well as necessary interventions. It enables practitioners at the local level to ensure the equitable and sustainable extension of water, sanitation and hygiene services; ICT can be integrated into monitoring and evaluation frameworks to optimize operations [10]

ICT and energy efficiency are connected in two ways: 'Greening of ICTs' and 'Greening through ICTs' [10]. Mission-critical communications is essential for power utilities. The digitalization of power utilities is expected to bring sustainable power efficiency to increase quality and potential cost savings to end consumers [14]

Mobile communications can increase market size by online channels with consumer connectivity and provide access to mobile financial services for companies [42]. In 2018, mobile technologies and services generated $\$ 3.9$ trillion of economic value (4.6\% of GDP) globally, a contribution that will reach $\$ 4.8$ trillion ( $4.8 \%$ of GDP) by 2023 [42]. ICT skills are a prerequisite for almost all forms of employment. ICT transforms the way that business is being done everywhere and creates new employment opportunities [10] 
Table 1 (continued)

\section{UN SDG Connection to mobile communications}

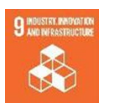

Mobile networks are critical infrastructures for providing affordable access to voice and data services and connecting remote areas to employment opportunities. They connect people to opportunities to improve their lives through access to education, enhanced healthcare, information and public services and market opportunities. They also connect people to things and things to things creating more efficient and sustainable possibilities [14]. IoT solutions can be used for sustainable manufacturing [9, 42]. Broadband is essential infrastructure due to its capacity to power industry and innovation; globally harmonized spectrum and standards are essential to facilitate the development of transformative digital infrastructure [10]. The development of resilient infrastructure relies on secure digital solutions for monitoring and efficient management [15]

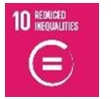

Mobile communications enable access to information/social networks to promote social and political inclusion, allow access to marketplaces, and facilitate mobile money and digital identity services [42]. ICT enables access to information and knowledge to disadvantaged segments of society-including those living with disabilities, as well as women and girls [10]

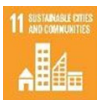

Advanced communications techniques can attract and retain workers in rural areas by improving the teleworking experience, allowing for collaborative innovation systems among firms and research centers. They also help to increase efficiency of rural business and training of workers. Self-driving cars can improve public transport and increase attractiveness to live and work in rural areas, while drones can boost productivity of rural business, improve access to goods, and reduce productions and delivery costs [44]. Internet of Things (IoT), data insights, and the 5G-based solutions enable smart, sustainable solutions e.g., in public transport, traffic control and real-time monitoring of air quality [15]

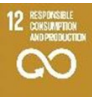

Increased dematerialization and virtualization, and innovative ICT applications, enable sustainable production and consumption. Cloud computing, smart grids, smart metering, and reduced energy consumption of ICTs positively impact reducing consumption. ICT energy consumption and negative impacts of ICTs, such as e-waste, need to be minimized [10]. The internet gives consumers and prosumers direct access to services that replace physical products and support growing service economies [15]. AI, IoT, blockchain, and sensors are already bringing greater efficiency across industries and transparency to supply chains. They also help improve production, circularity and consumption. A circular approach to business enhances efficient, less wasteful consumption while also reducing the need for virgin natural resources. Asset recovery services enable recycling, reuse and refurbishment of old telecommunications equipment [14]

Mobile communication can help avoid greenhouse gas (GHG) emissions by enabling other sectors to reduce their GHG emissions, facilitate smart traffic management, smart urban lighting, smart parking, smart logistics, building energy management systems, remote working, sharing economy, smart grids, connected health, and precision agriculture [9]. Radio access sites consume approximately 80 percent of a mobile network's energy. Novel context aware solution bring increased energy efficiency, and renewable energy decarbonizes the radio sites energy consumption [14]

ICT facilitates conservation and sustainable use of the oceans through improved monitoring and reporting delivering timely and accurate data, while local sensors deliver updates in real-time. Big data can be used to analyze the short-term and long-term trends in areas like biodiversity, pollution, weather patterns and ecosystem evolution, and plan needed mitigation activities [10]. Enabling technologies in the ocean economy can improve data quality, data volumes, connectivity, and communication from the depths of the sea. Blockchain and big data analytics applications are being deployed in port facilities and maritime supply chains, autonomous ships and autonomous underwater vehicles (AUVs) [44]

ICT allows conservation and sustainable use of terrestrial ecosystems and the prevention of biodiversity loss through improved monitoring and reporting by delivering timely and accurate data globally, while local sensors can deliver on-the-spot updates in real-time. Big data can be used to analyze short- and long-term trends in terms of biodiversity, pollution, weather patterns and ecosystem evolution, and to plan mitigation activities [10] 
Table 1 (continued)

UN SDG Connection to mobile communications

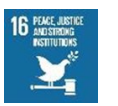

Mobile technology for authorities (e.g., police) helps prevent violence and adheres strict data privacy and security policies aligned with national and international law [42]. The growing use of open data by governments increases transparency, empowers citizens, and helps to drive economic growth by record-keeping and tracking government data and local demographics. In natural or other disasters, ICT can help obtain, communicate and transmit accurate and timely information [10]. Connectivity is a social good that can support human rights by enabling free expression, exchange of ideas, education and economic development [14]. The sense of community created by $6 \mathrm{G}$ technology and the collaborating directly with others enables humans to participate and act in society unprecedentedly in countries where access to new technologies is the norm due to competences and skills in using new technologies [3]

The mobile sector supports collaboration between the public and private sectors [9]. ICT is crucial in achieving all of the SDGs since ICT acts as catalysts that accelerates all three pillars of sustainable development-economic growth, social inclusion and environmental sustainability - and provide an innovative and effective means of implementation in today's inter-connected world [10]. The ICT industry is increasingly adoptin the ecosystem approach. Partnering with a broad range of stakeholders helps to unlock the potential of digital solutions that are the drivers for sustainable development, and in managing industry-common and crossindustry challenges [15]. The sharing economy, crowdsourcing, and crowdfunding expand the space for new forms of organization and innovation [3]

\section{The Vision of Future 6G Mobile Communication Networks}

While the deployment of $5 \mathrm{G}$ is well underway, the research community has already launched dedicated efforts to investigate what comes after $5 \mathrm{G}$. The research on $6 \mathrm{G}$ is in the early phase, aiming at the first deployments of $6 \mathrm{G}$ mobile communication networks starting in 2030. Together with the telecommunication industry, the research community made the world's first 6G White Paper in 2019 [21] as a collaborative effort of 70 experts globally, led by the Finnish 6G Flagship. In this first joint vision of $6 \mathrm{G}$ presented in [21], $6 \mathrm{G}$ is expected to merge traditional communication service with sensing, imaging, and highly accurate positioning capabilities and mobility, which in turn can open the door for a myriad of new applications. Another key finding in the white paper was the consensus that the UN SDGs should be a key driver for $6 \mathrm{G}$ research and development.

In a set of 12 follow up 6G White Papers from the 6G Flagship prepared in collaboration with 250 experts from 100 organizations in over 30 countries [51], selected themes were revisited in more detail, including UN SDGs; business scenarios; validation and trials; remote area connectivity; networking; machine learning; edge intelligence; trust, security and privacy; broadband connectivity; machine-type communications; localization and sensing; and RF aspects. The 6G technology aims at becoming a general-purpose technology [43], instead of merely an enabling technology. General-purpose technology (GPT) can be defined as (1) being pervasive, (2) having dynamism for continuous technical improvements, and (3) enabling innovational complementarities across a wide range of industry sectors [52]. While a GPT progresses and advances, it spreads throughout the economy, bringing about and fostering generalized productivity gains. GPT, which typically drives technological change in an industry and is used widely by downstream applications, has large positive static and dynamic spillovers [53].

From the business perspective, $6 \mathrm{G}$ is expected to offer novel business scenarios, like which were not envisioned for $5 \mathrm{G}$ at such a large scale. Special emphasis in the $6 \mathrm{G}$ business scenarios developed in [43] is put on scenarios for sustainability [54]. Authors in [43] 
identify key trends that are closely connected with the development and future implementation of $6 \mathrm{G}$. These include societal and political trends such as geopolitics, public network funding and issues concerning the ownership of data or governance of the spectrum, and technological aspects such as developing AI and mobile communication technologies in general. Also, issues regarding both technology and policy have to be solved, such as cybersecurity and privacy. $6 \mathrm{G}$ can advance the goals by creating disruptive business models and enabling the breaking down of barriers. From the legal and regulatory perspective, $6 \mathrm{G}$ can improve and create public services and access to them (such as health care, education) and contribute to the sustainable use of resources, such as water or land. The use and ownership of spectrum and data continue to be key issues ultimately shaping the business ecosystem. $6 \mathrm{G}$ will need to be developed to fully address the requirements for sustainability, for example, for improved resource efficiency, including energy efficiency [3, 43].

A $6 \mathrm{G}$ vision presented in [55] envisages new services, such as holographic communications and technological enablers, including sub-terahertz and visible light communications and more generally massive use of multi-radio access technologies and multilink techniques. At the architectural level, new approaches are expected for delay-sensitive AI applications. Another 6G vision presented in [56] introduces a large-dimensional and autonomous network architecture integrating space-air-ground-underwater networks for providing full coverage and unlimited wireless connectivity. 6G vision in [57] introduces additional senses and emotions as $6 \mathrm{G}$ applications, proposes ultra-long battery life as a key requirement, and highlights the importance of the socio-technical design of $6 \mathrm{G}$. 6G vision in [58] highlights photonics and AI as disruptive technologies for 6G. According to a comprehensive survey on 6G in [59], 6G will accommodate use cases introduced in 5G with a better quality of experience in a more cost-efficient, energy-efficient, and resource-efficient manner. 6G will also enable new use cases, e.g., holographic-type communications, pervasive intelligence, and ubiquitous global connectivity, and introduce the expansion from only human-centric to also connecting machines and things. The 6G vision in [60] expects new themes to emerge, such as new man-machine interfaces, ubiquitous universal computing, multi-sensor data fusion, and precision sensing and actuation to control the physical world. Quantum machine learning for 6G is reviewed in [61], where a 6G vision of a massively connected complex network, capable of rapidly responding to the users' service calls through real-time learning of the network state, is introduced. In the context of $6 \mathrm{G}$, trust, security, and privacy will become an ever-increasing priority [62].

The European Hexa-X project's 6G vision presented in [63] and developed in collaboration with 25 organizations is to connect the worlds and revolve around their interaction: a human world of our senses, bodies, intelligence, and values; a digital world of information, communication, and computing; and a physical world of objects and organisms. The following six main research challenges were identified: connecting intelligence, the network of networks (e.g., millions of (specialized) subnetworks), sustainability, global service coverage, extreme experience, and trustworthiness.

Figure 2 summarizes elements of the $6 \mathrm{G}$ vision from multiple sources.

\section{Sustainable Development and 6G}

The first connection between UN SDGs and 6G was created in the world's first 6G White Paper [21] that concluded that $6 \mathrm{G}$ development should be aligned with the UN SDGs. After reaching this consensus, further work on the connection between $6 \mathrm{G}$ and UN SDGs 


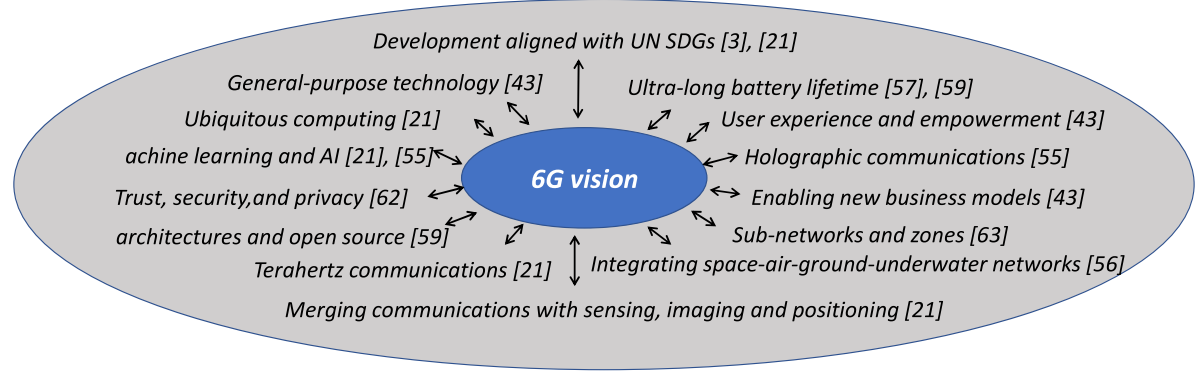

Fig. 2 Elements of $6 \mathrm{G}$ vision towards a general-purpose technology

was done in a continuation 6G White Paper [3], where 40 experts globally developed the linking and a vision for 6G. The work identified a three-fold role for 6G: as (1) provider of services to help to reach the UN SDGs, (2) enabler of measuring tools for data collection to help with the reporting of indicators, and (3) reinforcer of a new ecosystem to be developed in line with the UN SDGs.

The white paper [3] further developed a methodology for connecting 6G and UN SDGs through the existing indicators of the UN SDG framework. In the UN SDG framework, only 7 of the 231 individual indicators are directly related to ICT, but the ICT sector can influence many other targets as measured through the individual indicators. The white paper [3] analyzed how $6 \mathrm{G}$ can contribute to the different targets within the SDGs via these existing indicators. The white paper also launched the process of developing a new set of indicators for $6 \mathrm{G}$, taking into account the proposed three-fold role of $6 \mathrm{G}$. The white paper also outlined a preliminary action plan where different stakeholders, including research and educational organizations, governments, standards developers, users, MNOs, network equipment manufacturers, application and service providers, and verticals, were invited to think out-of-the-box and create new technology solutions and collaborative business models, intending to support the achievement of the UN SDGs. The novel observation in the white paper [3] was that the future 6G systems, where the communication capabilities are merged with sensing, location, imaging, and other capabilities, could gather a variety of data to report on the achievement of the UN SDGs on a highly local granularity level. This could respond to the challenge that nations face in reporting the indicator data on achieving the UN SDG framework targets. The UN SDG framework is likely to evolve during the full deployment of $6 \mathrm{G}$ in the 2030s.

Authors in [64] present a survey of the 6G ecosystem and summarize KPIs for the UN SDGs, including, e.g., coverage, frequency, connectivity, data rate, \% ICT ready cities, \% smartphones. Energy self-sustainability is proposed for 6G in [65] where zero energy 6G devices are envisaged. The survey on green $6 \mathrm{G}$ technologies in [31] focuses on sustainability in the wireless evolution towards $6 \mathrm{G}$ networks in architectural changes, energy harvesting, and flexible and intelligent materials.

The 6G vision of [63] introduces Key Value Indicators (KVIs), capturing trustworthiness, inclusiveness, and sustainability of $6 \mathrm{G}$, and sees $6 \mathrm{G}$ as an enabler for sustainability. Up to $5 \mathrm{G}$, the dominant paradigm used in assessing and comparing technological solutions and generations has been to use KPIs (key performance indicators). However, in $6 \mathrm{G}$, the KPIs will be extended to comprise KVIs [66] related to different aspects of sustainability [63]. Thus, introducing and implementing sustainability to mobile communications calls for a process of dealing with numerous interacting metrics that 
consider the emerging, enabling and embedding nature of technology across the economic, societal, and environmental perspectives on sustainability. Quantifying qualitative metrics related, e.g., to user experience and comprising various collective societal factors like privacy or freedom and environmental factors from different stakeholder perspectives is challenging; applying these new metrics to technology development calls for careful consideration.

Figure 3 illustrates the interrelated societal, economic, and environmental sustainability perspectives in the sustainable development of 6G. Sustainability requirements will need to be translated into new KPIs for $6 \mathrm{G}$ that will drive the development of $6 \mathrm{G}$ technical enablers and technology components that will need to be standardized to reach economies of scale. Some of these technology components could also be used as measuring tools for collecting data on sustainability. Economic sustainability will lead to the emergence of a new $6 \mathrm{G}$ business ecosystem with new stakeholders and roles and possibly conflicting views on how business could be conducted. KVIs stemming from societal sustainability aspects will be needed for $6 \mathrm{G}$, especially to indicate how well $6 \mathrm{G}$ can help all aspects of society reach UN SDGs.

\section{Future Research Challenges for Sustainable Development of 6G}

Next, we discuss open research challenges for sustainable development of $6 \mathrm{G}$ for the wireless and mobile communications research community. Sustainability in this context is more than traditionally considered green communications to optimize energy efficiency, and it opens up important research topics for the development of 6G, addressing economic, societal, and environmental perspectives of sustainability.

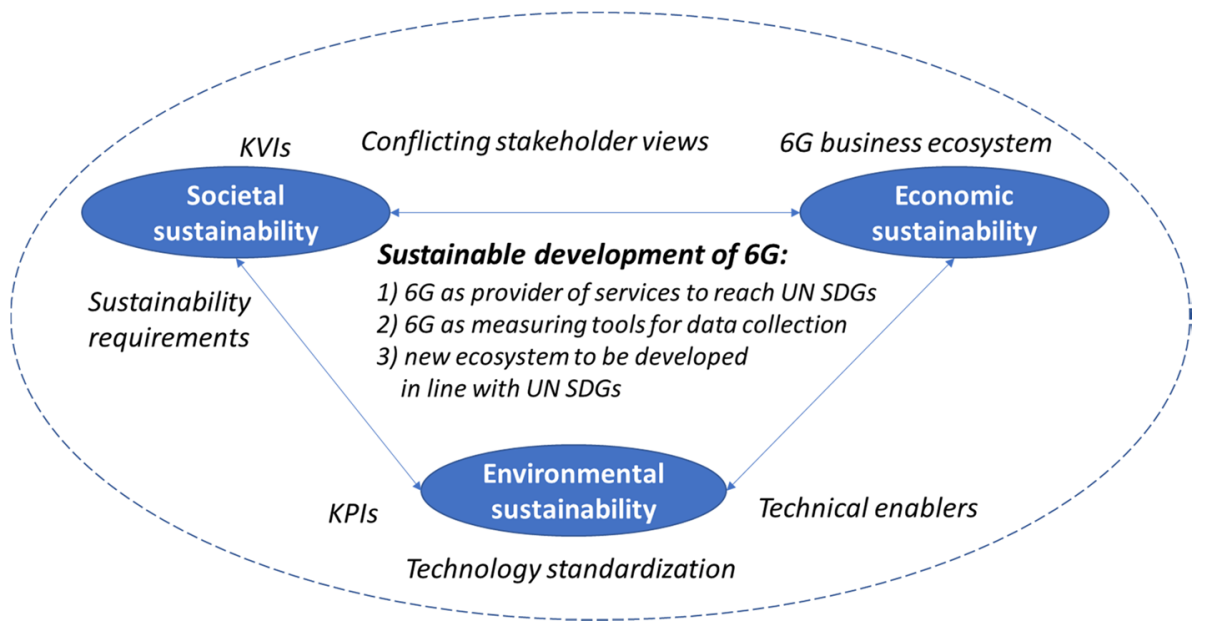

Fig. 3 Societal, economic and environmental sustainability perspectives in the sustainable development of $6 \mathrm{G}$ 


\subsection{Economic Sustainability}

Economic value and sustainability have for long been evaluated at the firm, network, industry, ecosystem, and market levels of analysis with measures like revenues, margins, profits, and asset value. However, in developing new technologies, such as 6G, this kind of retrospective measures are not practical considering the emerging, enabling, and embedding nature of new technology and the economic, societal, and environmental expectations placed on new technologies in general by different stakeholders. New technologies should be profitable, affordable, and have positive spillover and network effects [67]. In developing new technologies, a practical way to plan for economic sustainability is to focus on the opportunities, value creation potential, and advantages of the developed technology and contribute to the scalability and replicability of that technology [43]. Resilience, in turn, is influenced by the scalability, replicability, and sustainability of technology. Resilience refers to the capacity of a human system, such as an individual business, business sector, local community, or the wider society, to absorb disturbance and reorganize their functionality while undergoing a change or even severe shocks. Thus, it has two sides, absorption and adaption, concerning the change. Resilience and integrated sustainability can be seen as co-evolving, or resilience may be interpreted as an economic, societal, and environmental sustainability outcome. People, communities, and societies can become stronger and more resilient as they use and develop novel $6 \mathrm{G}$ technologies.

Regarding 6G, the question is whether it can become a true general-purpose technology like the Internet and not just an important enabling technology. While enabling technologies are upgradable and adaptable, have improvement potential and broad applicability [68], general-purpose technologies are "characterized by the potential for pervasive use in a wide range of sectors and by their technological dynamism" [52]. As general-purpose technologies evolve and advance, they spread throughout the economy, bringing about and fostering productivity. However, most general-purpose technologies remain enabling technologies that open up new opportunities rather than offer complete, final solutions.

The collaborative research and standardization development have enabled massive growth in mobile communication technology and downstream application innovation ecosystems. 6G can be defined as an emerging general-purpose technology being ubiquitous, enabling continuous technical improvements, and empowering innovational complementarities across industry sectors via open value configuration and ecosystem-focused business model. From the policy perspective, there is a trend towards the strengthened public-private-partners model in which the governments will have a stronger role in funding the key enabling technologies and GPTs. The counterforces to winner-takes-all monopolies include platform cooperatives, the peer-to-peer economy and sharing economic models, and the progress of the human-driven fair data economy and the fair distribution of wealth. This restorative economy will lead to a society characterized by broad empowerment, greater equality, a higher level of well-being, and better sustainability. Key issues in 6G will be the regulation of multi-sided platforms and the governance of privacy and security of users, impacting the data protection and artificial intelligence (AI) rights particularly.

The collaborative research and standardization development have enabled massive growth, especially in mobile communication technologies and downstream application innovation ecosystems. $6 \mathrm{G}$ can be defined as an emerging general-purpose technology being ubiquitous, enabling continuous technical improvements, and empowering innovational complementarities across industry sectors via open value configuration and ecosystem-focused business model. 


\subsection{Societal Sustainability}

The sense of community created by $6 \mathrm{G}$ technology and the ability to collaborate with others directly enable people to participate and act in society in a new way. Co-evolution of humans and technologies and people co-creating digital futures is part of their everyday lives and practices at work and leisure time. It is essential to always consider whether users have real access to digital services needed in everyday lives: that they have the necessary devices and know how to use those and the available services. There is a serious need to consider non-users and why they are excluded; is it by their own choice or for some other reason. A deeper understanding of technology in the form of technology development skills such as, e.g., programming or digital fabrication also further enhances the users' possibilities to take an active role in the ecosystem and make and shape technologies for their personal needs. This helps the users evaluate and reflect on the technologies and their role in the user's own life and, more widely, in the society: Who benefits from technology or service use, and how? Who experiences value? What is the real price, and is it worth paying? Furthermore, future research is needed to explore how user empowerment can be ensured in this context. Do users have a genuine opportunity to play an active role in the ecosystem, including design techniques for experimenting, making, and shaping technologies for their personal needs? In addition, how can users be assisted to take a reflective approach to technology use so they can evaluate and reflect on the role and value of technology in their everyday life contexts and more widely in society?

\subsection{Environmental Sustainability}

Environmental sustainability in $6 \mathrm{G}$ will go beyond traditional resource efficiency considerations. Yet, the $6 \mathrm{G}$ systems need to critically address energy efficiency and end-to-end energy consumption, for which new measures and measurement methods are urgently needed. Environmental sustainability in $6 \mathrm{G}$ can be considered using the 6R approachreduce, reuse, recycle, recover, remanufacture, and redesign- originally developed to assess the sustainability of manufactured goods [25] guide us in the development of new 6G technologies. Table 2 summarizes open challenges for sustainable development using this approach. 'Reduce' provides guidelines for reducing resource usage, energy consumption, waste, radiation, and other emissions with possible health hazards, which in the context of $5 \mathrm{G}$ and $6 \mathrm{G}$ have become increasingly important concerns of end-users. 'Reuse' points to the use of reusable materials in general at product (including its components and complements and extensions), process, and (eco)systems levels over the whole lifecycle of a technology. This ecosystem-level should also include the users and the whole social context of the deployment of technology. In the $6 \mathrm{G}$ context, massive reuse of existing physical and hardware infrastructure as well as software will be important from a sustainability perspective. In turn, 'Recycle' refers to converting waste and other byproducts of technology into something usable after original use. Of specific importance in this regard is data. 'Recover' denotes collecting end-of-life products and other artifacts and outcomes and recovering what is reusable for (other) post-use. For $6 \mathrm{G}$, this could refer to how the different generations of mobile communications networks in different phases in their lifecycle could be used to minimize their burden on sustainability. 'Redesigning' offers flexibility for remanufacturing process but especially allows for complementarity and extendibility of technology and its function. It also refers to considering the changing societal values and aspects 


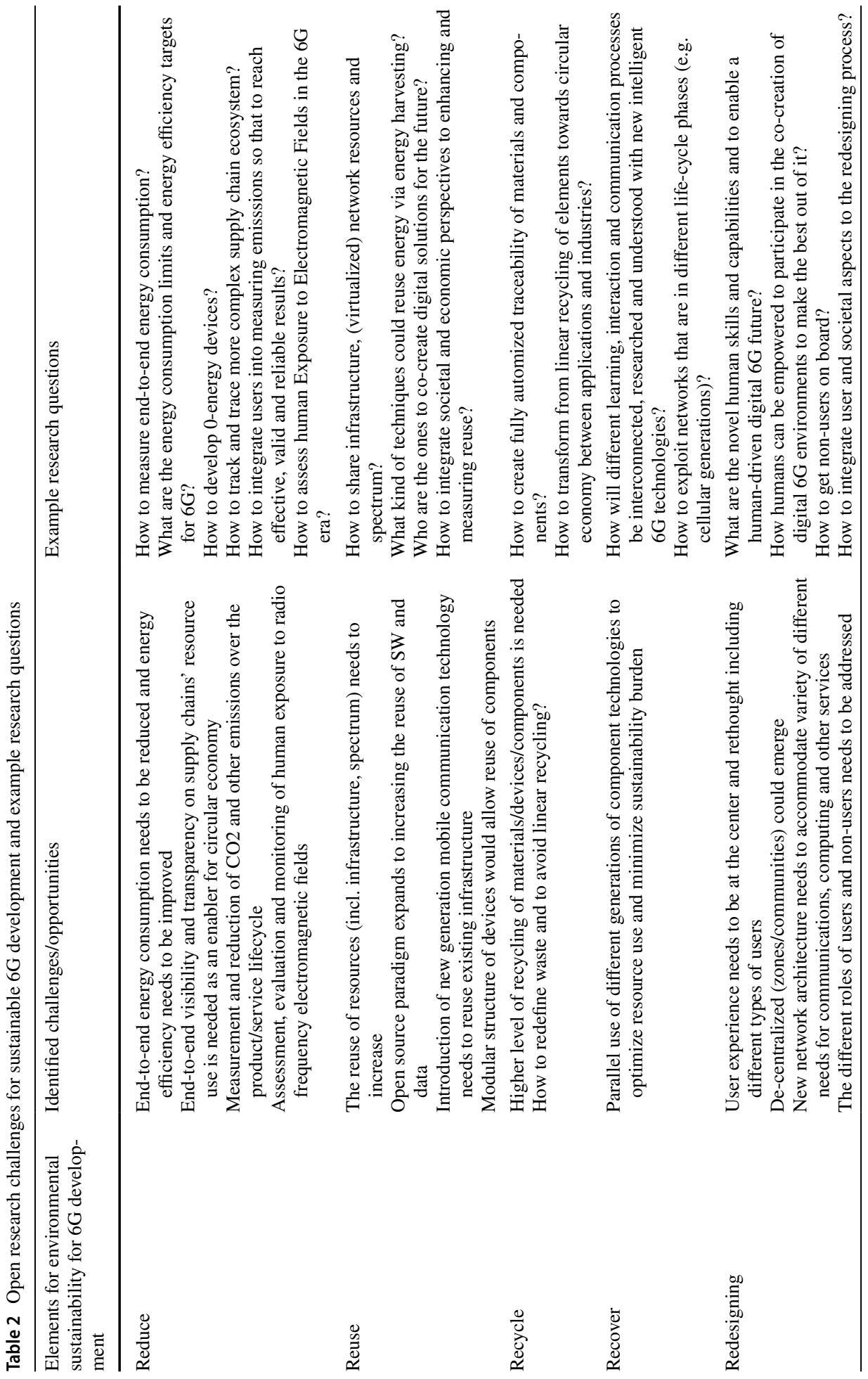




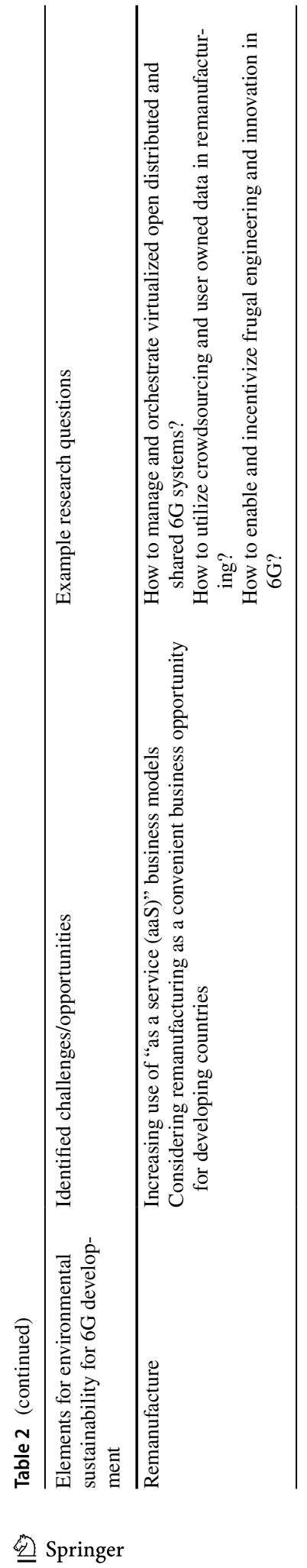


of use. In 6G, end users' needs will need to be in the focus of the development. Finally, 'remanufacture' refers to the re-processing of used products, processes, and systems or their restoration to the original state or possible new form. in $6 \mathrm{G}$, it could lead to increased use of "as a service (aaS)" business models where e.g., infrastructure is not purchased but consumed as a service.

\section{Conclusions}

This paper has introduced sustainability discussions into the wireless and mobile communications research domain, covering societal, economic, and environmental aspects of sustainable development. The paper has specifically addressed the UN SDG framework for developing mobile communication systems and highlighted the close connection between these two. We have summarized the current sustainability discussions within mobile communications, which focus on environmental sustainability largely through resource efficiency considerations. We have then proceeded to the sustainable development of the next-generation mobile communication systems $(6 \mathrm{G})$ to connect $6 \mathrm{G}$ and the UN SDGs, both targeted for 2030. We have summarized $6 \mathrm{G}$ research visions and noted that sustainability is seen as a key driver for $6 \mathrm{G}$ research and development. However, the approaches so far remain rather traditional, focusing on environmental sustainability. We have introduced new approaches to sustainability into $6 \mathrm{G}$ research and development through societal, economic, and environmental sustainability perspectives. New research is needed to better integrate the economic, societal, and environmental sustainability perspectives together at the practical level for developing new technology. Researchers in the wireless and mobile communications sector are highly encouraged to bring sustainability into their day-to-day research to develop sustainable solutions for realizing a sustainable future.

Acknowledgements The authors would like to acknowledge 6G Flagship expert group that prepared the White Paper on 6G Drivers and the UN SDGs. Funding from Academy of Finland through 6G Flagship (grant 318927) is acknowledged.

Authors' Contributions Optional: please review the submission guidelines from the journal whether statements are mandatory.

Funding Open access funding provided by University of Oulu including Oulu University Hospital. This research is supported by Academy of Finland through 6Genesis Flagship (Grant 318927).

Data Availability None.

Code availability None.

\section{Declarations}

Conflicts of interest The authors declared that they have no conflict of interest.

Open Access This article is licensed under a Creative Commons Attribution 4.0 International License, which permits use, sharing, adaptation, distribution and reproduction in any medium or format, as long as you give appropriate credit to the original author(s) and the source, provide a link to the Creative Commons licence, and indicate if changes were made. The images or other third party material in this article are included in the article's Creative Commons licence, unless indicated otherwise in a credit line to the material. If material is not included in the article's Creative Commons licence and your intended use is not permitted by statutory regulation or exceeds the permitted use, you will need to obtain permission directly from the copyright holder. To view a copy of this licence, visit http://creativecommons.org/licenses/by/4.0/. 


\section{References}

1. UN. (2015). Resolution adopted by the General Assembly on Transforming our world: The 2030 agenda for sustainable development (A/RES/70/1). United Nations, October 2015. https://www.un.org/ ga/search/view_doc.asp?symbol=A/RES/70/1\&Lang=E

2. European Commission. European Green Deal. https://ec.europa.eu/info/strategy/priorities-2019-2024/ european-green-deal/actions-being-taken-eu_en

3. Matinmikko-Blue, M. et al. (Eds.). (2020). White paper on 6G drivers and the UN SDGs [White paper]. (6G Research Visions, No. 2). University of Oulu. http://urn.fi/urn:isbn:9789526226699

4. Elkington, J. (1998). Partnerships from cannibals with forks: The triple bottom line of 21st-century business. Environmental Quality Management, 8(1), 37-51.

5. Miceli, A., Hagen, B., Riccardi, M. P., Sotti, F., \& Settembre-Blundo, D. (2021). Thriving, not just surviving in changing times: How sustainability, agility and digitalization intertwine with organizational resilience. Sustainability, 2021(13), 2052.

6. Khan, I. S., Ahmad, M. O., \& Majava, J. (2021). Industry 4.0 and sustainable development: A systematic mapping of triple bottom line, circular economy and sustainable business models perspectives. Journal of Cleaner Production, 126655.

7. Jabbour, C. J. C., Fiorini, P. D. C., Ndubisi, N. O., Queiroz, M. M., \& Piato, É. L. (2020). Digitallyenabled sustainable supply chains in the 21st century: A review and a research agenda. Science of The Total Environment, 725, 138177.

8. UNESCO. (2021). Information and communication technologies (ICT). Definition. http://uis.unesco.org/en/glossary-term/information-and-communication-technologies-ict

9. GSMA. (2020). 2020 Mobile industry impact report: sustainable development goals. September 2020.

10. ITU. (2021). ICTs for a ICTs for a sustainable world \#ICT4SDG. https://www.itu.int/en/susta inable-world/

11. Ministry of Transport and Communications Finland. (2021). Climate and environmental strategy for the ICT sector. Publications of the Ministry of Transport and Communications 2021:6, Finland. http://urn.fi/URN:ISBN:978-952-243-595-8

12. Bieser, J. C., \& Hilty, L. M. (2018). Assessing indirect environmental effects of information and communication technology (ICT): A systematic literature review. Sustainability, 10(8), 2662.

13. UN. Sustainable development goals. United Nations. https://www.un.org/sustainabledevelopment/

14. Nokia. (2020). Nokia and the United Nations sustainable development goals. https://www.nokia.com/ about-us/sustainability/our-approach/nokia-and-the-united-nations-sustainable-development-goals/

15. Telia. (2020). Telia company annual and sustainability report 2020. https://www.teliacompany.com/ globalassets/telia-company/documents/reports/2020/annual/telia-company--annual-and-sustainabi lity-report-2020.pdf

16. Broadband Commission. (2020). The state of broadband: Tackling digital inequalities: A decade for action. https://www.broadbandcommission.org/publication/the-state-of-broadband-2020/

17. Wu, J., Guo, S., Huang, H., Liu, W., \& Xiang, Y. (2018). Information and communications technologies for sustainable development goals: State-of-the-art, needs and perspectives. IEEE Communications Surveys \& Tutorials, 20(3), 2389-2406.

18. Higón, D. A., Gholami, R., \& Shirazi, F. (2017). ICT and environmental sustainability: A global perspective. Telematics and Informatics, 34(4), 85-95.

19. Belkhir, L., \& Elmeligi, A. (2018). Assessing ICT global emissions footprint: Trends to 2040 \& recommendations. Journal of Cleaner Production, 177, 448-463.

20. Tjoa, A. M., \& Tjoa, S. (2016). The role of ICT to achieve the UN sustainable development goals (SDG). In IFIP world information technology forum (pp. 3-13). Springer.

21. Latva-aho, M. \& Leppänen, K. (Eds.) (2019). Key drivers and research challenges for 6G ubiquitous wireless intelligence. [White paper]. (6G Research Visions, No. 1). University of Oulu, Finland. http://urn.fi/urn:isbn:9789526223544

22. Teece, D. J. (2018). Profiting from innovation in the digital economy: Enabling technologies, standards, and licensing models in the wireless world. Research Policy, 47(8), 1367-1387.

23. Kapoor, R., \& Teece, D. J. (2021). Three faces of technology's value creation: emerging, enabling. Embedding. Strategy Science, 6(1), 1-4.

24. Ranjbari, M., Esfandabadi, Z. S., Zanetti, M. C., Scagnelli, S. D., Siebers, P. O., Aghbashlo, M., \& Tabatabaei, M. (2021). Three pillars of sustainability in the wake of COVID-19: A systematic review and future research agenda for sustainable development. Journal of Cleaner Production, 126660 . 
25. Joshi, K., Venkatachalam, A., \& Jawahir, I. S. (2006). A new methodology for transforming 3R concept into 6R concept for improved product sustainability. In Proceedings of the IV global conference on sustainable product development and life cycle engineering, Sao Carlos.

26. Maqbool, Y., Rafique, M. Z., Hussain, A., Ali, H., Javed, S., Amjad, M. S., \& Atif, M. (2019). An implementation framework to attain 6R-based sustainable lean implementation-A case study. IEEE Access, 7, 117561-117579.

27. Matthews, N. E., Stamford, L., \& Shapira, P. (2019). Aligning sustainability assessment with responsible research and innovation: Towards a framework for constructive sustainability assessment. Sustainable Production and Consumption, 20(2019), 58-73.

28. Georgakopoulos, A., Margaris, A., Tsagkaris, K., \& Demestichas, P. (2016). Resource sharing in 5G contexts: Achieving sustainability with energy and resource efficiency. IEEE Vehicular Technology Magazine, 11(1), 40-49.

29. Zhang, S., Wu, Q., Xu, S., \& Li, G. Y. (2017). Fundamental green tradeoffs: progresses, challenges, and impacts on $5 \mathrm{G}$ networks. IEEE Communications Surveys \& Tutorials, 19(1), 33-56.

30. Huang, T., Yang, W., Wu, J., Ma, J., Zhang, X., \& Zhang, D. (2019). A survey on green 6G network: Architecture and technologies. IEEE Access, 7, 175758-175768.

31. Zhang, S., Xu, S., Li, G. Y., \& Ayanoglu, E. (2020). First 20 years of green radios. IEEE Transactions on Green Communications and Networking, 4(1), 1-15.

32. Suryanegara, M., Arifin, A. S., Asvial, M. \& Ramli, K. (2018). The use of 5G mobile technology in creating a sustainable society: A systems engineering approach. 2018 Second world conference on smart trends in systems, security and sustainability (WorldS4), London (pp. 140-144).

33. Rapone, D., Sabella, D. \& Fodrini, M. (2015). Energy efficiency solutions for the mobile network evolution towards 5G: An operator perspective. 2015 Sustainable internet and ICT for sustainability (SustainIT), Madrid, Spain (pp. 1-9).

34. Gonçalves, L. C., Sebastião, P., Souto, N. \& Correia, A. (2016). 5G mobile challenges: A feasibility study on achieving carbon neutrality. In 2016 23rd International conference on telecommunications (ICT), Thessaloniki, Greece (pp. 1-5).

35. Masoudi, M., et al. (2019). Green mobile networks for 5G and beyond. IEEE Access, 7, 107270-107299.

36. Riekstin, A. C., et al. (2018). A survey on metrics and measurement tools for sustainable distributed cloud networks. IEEE Communications Surveys \& Tutorials, 20(2), 1244-1270.

37. Vatalaro, F., \& Ciccarella, G. (2020). A network paradigm for very high capacity mobile and fixed telecommunications ecosystem sustainable evolution. IEEE Access, 8, 135075-135090.

38. Mowla, M. M., Ahmad, I., Habibi, D., \& Phung, Q. V. (2019). Energy efficient backhauling for 5G small cell networks. IEEE Transactions on Sustainable Computing, 4(3), 279-292.

39. Bolla, R., Bruschi, R., Davoli, F., Lombardo, C. \& Pajo, J. F. (2020). Debunking the "Green" NFV Myth: An assessment of the virtualization sustainability in radio access networks. In 2020 6th IEEE conference on network softwarization (NetSoft), Ghent, Belgium (pp. 180-184).

40. Ono, T., Iida, K., \& Yamazaki, S. (2017). Achieving sustainable development goals (SDGs) through ICT services. Fujitsu Science Technology Journal, 53(6), 17-22.

41. Kostoska, O., \& Kocarev, L. (2019). A novel ICT framework for sustainable development goals. Sustainability, 11(7), 1961.

42. GSMA. (2018). Mobile industry impact report: Sustainable development goals. GSMA. https://www. gsma.com/betterfuture/wp-content/uploads/2020/05/2018-SDG-Impact-Report.pdf

43. Yrjölä, S., Ahokangas, P. \& Matinmikko-Blue, M. (Eds.). (2020a). White paper on business of 6G [White paper]. (6G Research Visions, No. 3). University of Oulu. http://urn.fi/urn:isbn:9789526226 767

44. OECD. (2019). Rethinking innovation for a sustainable ocean economy. OECD. https://doi.org/10. 1787/9789264311053-en

45. Biermann, F., Kanie, N., \& Kim, R. E. (2017). Global governance by goal-setting: The novel approach of the UN sustainable development goals. Current Opinion in Environmental Sustainability, 26, 26-31.

46. Eisenmenger, N., Pichler, M., Krenmayr, N., Noll, D., Plank, B., Schalmann, E., \& Gingrich, S. (2020). The sustainable development goals prioritize economic growth over sustainable resource use: A critical reflection on the SDGs from a socio-ecological perspective. Sustainability Science, 15, 1101-1110.

47. Wiedmann, T., Lenzen, M., Keyßer, L. T., \& Steinberger, J. K. (2020). Scientists' warning on affluence. Nature Communications, 11(1), 1-10.

48. Hu, A. H., Huang L. H. \& Chang, Y. (2016). Assessing corporate sustainability of the ICT sector in Taiwan on the basis of UN sustainable development goals. In 2016 Electronics goes green 2016+ (EGG), Berlin, Germany (pp. 1-6). 
49. Miller, L. et al. (2020). AI for monitoring the sustainable development goals and supporting and promoting action and policy development. In 2020 IEEE/ITU international conference on artificial intelligence for good (AI4G), Geneva, Switzerland (pp. 180-185).

50. UN. (2019). Global sustainable development report: The future is now-science for achieving sustainable development. United Nations. https://sustainabledevelopment.un.org/content/documents/24797 GSDR_report_2019.pdf

51. 6G Flagship. https://www.6gchannel.com/6g-white-papers/

52. Bresnahan, T. F., \& Trajtenberg, M. (1995). General purpose technologies: "Engines of growth"? Journal of Economics, 6(1), 83-108.

53. Carlaw, K. I., \& Lipsey, R. G. (2002). Externalities, technological complementarities and sustained economic growth. Research Policy, 31(8-9), 1305-1315.

54. Yrjölä, S., Ahokangas, P., \& Matinmikko-Blue, M. (2020). Sustainability as a challenge and driver for novel ecosystemic $6 \mathrm{G}$ business scenarios. Sustainability, 12, 21.

55. Calvanese Strinati, E., et al. (2019). 6G: The next frontier: From holographic messaging to artificial intelligence using subterahertz and visible light communication. IEEE Vehicular Technology Magazine, 14(3), 42-50.

56. Zhang, Z., et al. (2019). 6G Wireless networks: Vision, requirements, architecture, and key technologies. IEEE Vehicular Technology Magazine, 14(3), 28-41.

57. David, K., \& Berndt, H. (2018). 6G Vision and requirements: Is there any need for beyond 5G? IEEE Vehicular Technology Magazine, 13(3), 72-80.

58. Zong, B., Fan, C., Wang, X., Duan, X., Wang, B., \& Wang, J. (2019). 6G technologies: Key drivers, core requirements, system architectures, and enabling technologies. IEEE Vehicular Technology Magazine, 14(3), 18-27.

59. Jiang, W., Han, B., Habibi, M. A., \& Schotten, H. D. (2021). The road towards 6G: A comprehensive survey. IEEE Open Journal of the Communications Society, 2, 334-366.

60. Viswanathan, H., \& Mogensen, P. E. (2020). Communications in the 6G era. IEEE Access, 8, 57063-57074.

61. Nawaz, S. J., Sharma, S. K., Wyne, S., Patwary, M. N., \& Asaduzzaman, M. (2019). Quantum machine learning for $6 \mathrm{G}$ communication networks: State-of-the-art and vision for the future. IEEE Access, 7, 46317-46350.

62. Ylianttila, M. (Ed.). (2020). 6G white paper: Research challenges for trust, security and privacy [White paper]. (6G Research Visions, No. 9). University of Oulu.

63. Hexa-X. (2021). Expanded 6G vision, use cases and key societal values-including aspects of sustainability, security and spectrum. Hexa-X project Deliverable D1.2. https://hexa-X.eu/wp-content/uploads/2021/05/ Hexa-X_D1.2.pdf

64. Bhat, J. R., \& Alqahtani, S. A. (2021). 6G ecosystem: Current status and future perspective. IEEE Access, 9, 43134-43167.

65. Hu, J., Wang, Q., \& Yang, K. (2021). Energy self-sustainability in full-spectrum 6G. IEEE Wireless Communications, 28(1), 104-111.

66. Ziegler, V. \& Yrjola, S. (2020). 6G indicators of value and performance. In 2020 2nd 6 G wireless summit (6G SUMMIT), Levi, Finland (pp. 1-5).

67. Katz, M. L., \& Shapiro, C. (1994). Systems competition and network effects. Journal of Economic Perspectives, 8(2), 93-115.

68. Gambardella, A., Heaton, S., Novelli, E., \& Teece, D. J. (2021). Profiting from enabling technologies? Strategy Science, 6(1), 75-90.

Publisher's Note Springer Nature remains neutral with regard to jurisdictional claims in published maps and institutional affiliations. 

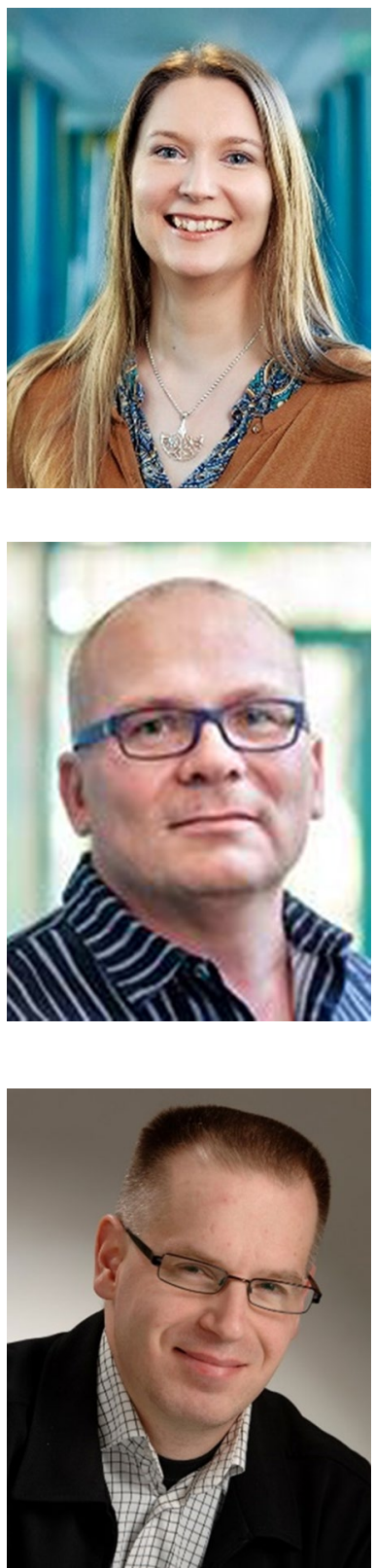

Dr. Marja Matinmikko-Blue is 6G Flagship Research Coordinator at Centre for Wireless Communications (CWC), University of Oulu, where she holds an Adjunct Professor position on spectrum management. She conducts multi-disciplinary research on technical, business and regulatory aspects of mobile communication systems in close collaboration with industry, academia and regulators. She holds a Dr.Sc. degree in telecommunications engineering and a Ph.D. degree in management sciences from University of Oulu from 2012 and 2018. She has coordinated several national research project consortia that have successfully demonstrated the world's first licensed shared access spectrum sharing trials and introduced a new local 5G operator concept that has become a reality. She has published $170+$ scientific publications and prepared $150+$ contributions to regulatory bodies in national, European and international levels. She coordinated the preparation of twelve 6G White Papers in 6G Flagship and led the development of the White Paper on 6G Drivers and the UN SDGs.

Dr. Seppo Yrjölä is a Principal Engineer at Nokia Enterprise Solutions, Finland. He holds a Dr. Sc. degree in Telecommunications Engineering from the University of Oulu and is a Professor of Practice at the Faculty of Information Technology and Electrical Engineering, University of Oulu in the field of techno-economics. He conducts multidisciplinary research combining technology, business and regulatory aspects. With roots in engineering and economics he explores how and why platform-based ecosystemic business models can emerge in the future wireless systems context.

Dr. Petri Ahokangas is the professor of Future digital business at Martti Ahtisaari Institute, Oulu Business School, University of Oulu, Finland and adjunct professor at Aalborg University, Denmark. Currently he is working within the 6G Flagship program at the University of Oulu. He received his M.Sc. and D.Sc. degrees from the University of Vaasa. His research interests are in the intersection of mobile communications, especially $5 \mathrm{G}$ and $6 \mathrm{G}$, and digital business creation and transformation in different industries and verticals. His specific research themes include future business models, ecosystems and strategies. Ahokangas has over 190 scientific publications and is actively working in several ICT focused research consortia. 


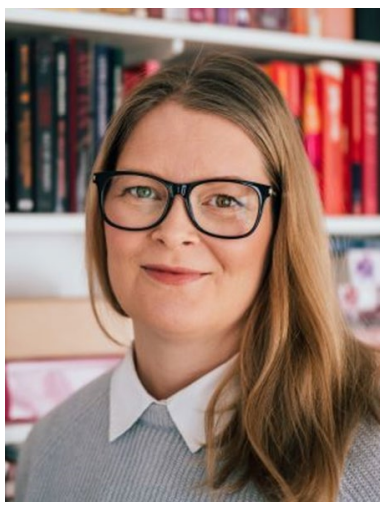

Kirsi Ojutkangas (M.A.) is a research funding specialist at University of Oulu where she is responsible for training and supporting researchers especially in Horizon Europe funding programme. Her interests lie in sustainability and research impact and she is a member of the University of Oulu's sustainability working group. She has published on impact in Social Sciences and Humanities (SSH), developed an online impact guide and participated in the development of the White Paper on 6G Drivers and the UN SDGs, in which she served as a chapter editor.

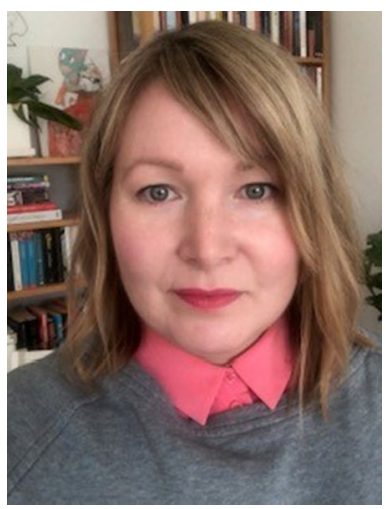

Elina Rossi (M.A.) is a specialist in research support in the Faculty of Information Technology and Electrical Engineering, University of Oulu. With a background in humanities, she has extensive experience in EU proposals and research funding, and training researchers on the related topics. Recently, she has focused on sustainability and research impact, for which she has developed an online guide. She is a member of the national sustainability group functioning under the Finnish Association of Research Managers and Advisors, and participated in the development of the White Paper on 6G Drivers and the UN SDGs, in which she served as a chapter editor. 